UDC: $621.39: 528.5$

DOI: $10.14438 / \mathrm{gn} .2014 .02$

\title{
Testing the Operational Quality of the Permanent GNSS stations network within AGROS RTK Service
}

\author{
Jelena GUČEVIĆ ${ }^{1 *}$, Stefan MILJKOVIĆ ${ }^{1}$ \\ ${ }^{1}$ University of Belgrade, Faculty of Civil Engineering, Belgrade, Serbia
}

\begin{abstract}
Using the Active Geodetic Reference Frame of Serbia (AGROS) RTK service one can determine spatial local reference network coordinates. Such network represents a local realization of the spatial reference system spreading over the area where a state survey is performed. We presented a research performed along the polygon used for student practice in 2012/13. The goal of the investigation was testing a quality and reliability of the AGROS network. We made a measurement plan for a ten days period. We controlled the quality of obtained results according to the parameters for following and controlling the measurements $\left(\sigma_{\mathrm{p}}<2 \mathrm{~cm}, \sigma_{\mathrm{h}}<3 \mathrm{~cm}, \mathrm{PDOP}<6\right)$. All calculations were done on WGS-84 ellipsoid in Cartesian coordinates, in order to avoid the error of the coordinate transformations into a projection plane.
\end{abstract}

Keywords: GNSS, RTK, reliability, AGROS, CORS

*Jelena Gučević> jgucevic@ @grf.bg.ac.rs 


\section{Introduction}

A geodetic network is the starting point for all surveying works within the state survey, requested for the real estate cadastre. In practice, the network consists of a set of permanently stabilized points with the coordinates determined in some coordinate system (State coordinate system, in the case of the state networks), which is used for surveying. Stabilization and the principles of the geodetic networks are same, but methods of the coordinate determination have evolved, following the technological development. Today, the current measuring method, i.e., determination of the geodetic network points, is represented by GPS surveying. Comparing to all ways of using GPS technology for surveying, the most favourable method became surveying using Continuously Operating Reference Stations (CORS) network.

CORS is represented by a set of stable and homogeneously distributed GNSS receivers working within the same system, continuously $24 \mathrm{~h}$ daily. The main task of the system is to enable precise positioning using just one receiver. The reference stations are connected to the monitoring centre which monitors their work and transmits data relevant to users. The networks are usually national or regional based and represent the reference frame of the system used in that particular area [6]. CORS network officially used within the territory of the Republic of Serbia is called Active Geodetic Reference Frame of Serbia (AGROS). It consists of 30 operative GPS/GNSS receivers regularly distributed along the territory of the state, at average distances of $70 \mathrm{~km} \mathrm{[3].}$

Within AGROS registered users can perform all geodetic and surveying measurements for the purpose of real estate cadastre. With respect to features that GPS technology can offer within the permanent stations network, a lot of users express their interest in applying this method for their projects realization. Accuracy that AGROS offers can be achieved only if a proposed procedure during the measurements is followed. That is why the users must strictly follow all manuals and procedures for measurements performing.

Reliability of AGROS measurements is still a sensitive topic, due to lack of the absolute accurate parameters that can guarantee achievement of the declared accuracy in any time and any place. Experiments and practise confirmed that in border regions significant problems can appear, which makes CORS networks unusable in those locations.

\section{Goals and research methods}

The goal of our research is presentation of necessary surveying activities requested for establishment of a new geodetic network along the polygon for the student practice in surveying, using the service AGROS-RTK. A special attention is paid to the reliability test and the control of the AGROS work. All calculations and testing are performed on WGS-84 ellipsoid and Cartesian coordinates. We emphasized the control of achieved results of the direct measurements. According to that, there will be no transformation into the plane of the state projection, in order to avoid the errors during the coordinate transformation, from WGS-84 to the state coordinate system.

In order to establish the new geodetic network using the GPS technology within the permanent stations network, we assumed the following surveying activities:

- reconnaissance and stabilization of the points,

- measurement,

- estimation of the final network points coordinates, and

- quality control of the obtained results.

Reconnaissance of the geodetic network assumes a choice for the certain spot in the field where a traverse point will be placed. The place for the point stabilization is chosen such that it provides both the persistence of the mark and the availability for measuring lengths, angles, GPS baselines, and surrounding objects and terrain. The persistence of the mark is provided by choosing the spot which is not exposed to significant movement due to sliding or other planned works which could cause destruction of the mark. For each newly stabilized traverse point, a position description is taken, which a surveyor enters in a form dedicated to the position description of the point [2].

Measurements for the purpose of establishment of the geodetic network are performed according to a manual prescribed by the Republic Geodetic Authority [4]. In order to provide a possibility of testing and quality control of the achieved results, we performed the measurements within ten measurement sessions. A time interval between two sessions was one day.

Estimation of the final points coordinates $(X$, $Y, Z)$ was accomplished by calculating the arithmetic mean of the measurements from three series, which was entered into the appropriate form 
(form GPS 5 - coordinate calculation). The coordinates are related to the WGS-84 ellipsoid.

Quality control of the obtained results is performed by comparison between different measurement epochs. Following our measurement plan, we measured the coordinates in ten epochs. From each epoch we obtain the final coordinates of all points, which mean that we collected ten measurements results for each point of the network. If there are three or more measurements of each quantity, there is a possibility for testing their mutual congruence.

One of the testing methods is to test a residual significance of a spatial deviation of each point from its zero value. The zero value can be chosen from one of the epoch values, calculated as the arithmetic mean or assumed to be equal to some other reliable measurements, if they exist.

Intensity (length) of baseline deviation of the point (Fig. 1) can be expressed by the formula:

$$
d_{i}^{e}=\sqrt{\left(X_{i}^{e}-X_{i}^{o}\right)^{2}+\left(Y_{i}^{e}-Y_{i}^{o}\right)^{2}\left(Z_{i}^{e}-Z_{i}^{o}\right)^{2}}
$$

with:

$i$ - point number,

$e$ - epoch number,

$d_{i}^{e}$ - length of deviation vector of $i$-th point from its zero value in $e$-th measurement epoch,

$P_{i}^{e}\left(X_{i}^{e}, Y_{i}^{e}, Z_{i}^{e}\right)$ - coordinate of measured point,

$$
P_{i}^{o}\left(X_{i}^{o}, Y_{i}^{o}, Z_{i}^{o}\right) \text { - coordinates of zero point. }
$$

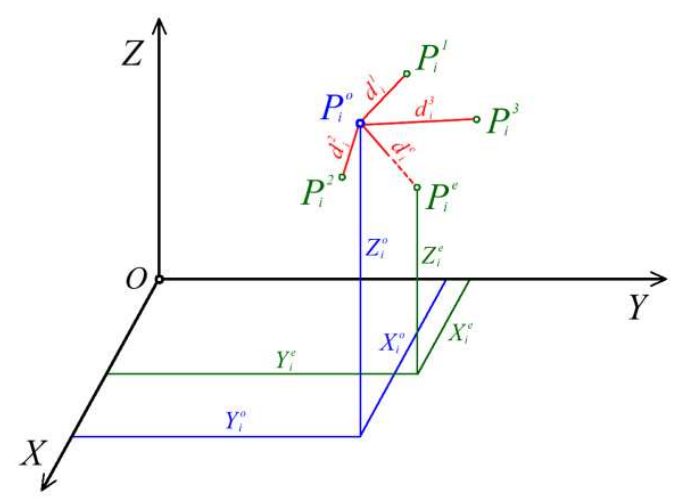

Figure 1: Coordinates residuals vector

According to (1) we calculated the residuals of each point for each measurement epoch. That is how we obtained an array of 10 lengths per point. Then we tested the significance of the differences comparing to the mean value, for each point.
We determined the average value of the array:

$$
\bar{d}_{i}=\frac{1}{n} \sum_{1}^{n} d_{i}^{e}
$$

where:

$\bar{d}_{i}$ - average array value,

$n$ - number of array elements (number of spatial lengths for the given point),

$e$ - number of the epoch.

We calculated a standard deviation of the array:

$$
\sigma_{d_{i}}^{2}=\frac{1}{n-1} \sum_{1}^{n}\left(d_{i}^{e}-\bar{d}_{l}\right)
$$

with:

$\sigma_{d_{i}-\text { standard deviation of the array, }}^{2}$

$d_{i}^{e}$ - length of the residual vector between $i$ th point and its zero value in $e$-th epoch measurement epoch,

$\bar{d}_{i}$ - average array value, and

$n$ - number of the array elements (number of spatial lengths for the given point).

We determined the minimal and maximal value of the average array value residual. In that way, we obtained the interval within which the residual values are placed:

$$
\begin{gathered}
\Delta d_{\text {max }}=\max \left(\left|d_{i}^{s}-\bar{d}_{i}\right|\right) \\
\Delta d_{\text {min }}=\min \left(\left|d_{i}^{s}-\bar{d}_{i}\right|\right)
\end{gathered}
$$

with:

$$
\begin{aligned}
& \Delta d_{\max } \text { - maximal residual, } \\
& \Delta d_{\min } \text { - minimal residual, } \\
& d_{i}^{e} \text { - length of the residual vector between } i \text { - }
\end{aligned}
$$
th point and its zero value in $e$-th measurement epoch,

$\bar{d}_{i}$ - average array value.

\section{Research area}

The area of Zlatibor mountain, according to its geographical position, as well as, numerous natural resources which it owns, represents a very specific area of Western Serbia. It is located about $220 \mathrm{~km}$ South-West from Beograde. The students practice, conducted by the Faculty of Civil Engineering in Belgrade, Department of Geodesy and 
Geoinformatics, was held here for the first time in summer 1992. Then we formed the polygon for practice, speeded along the territory of the settlement Zlatibor and its surroundings. In the same time, this represents the area where we performed our research. The polygon is located at the territory of the cadastral municipality Čajetina (K.O. Cajetina) with the area of about 500 ha, which is under jurisdiction of the political municipality and the cadastre of Cajetina. Cadastral data and satellite images of the location (Figure 2) are available, which is important for our research. The basic satellite images are downloaded from public Internet portals [7], which we used for the visualisation purposes regarding the surveyed points and the area of investigation.

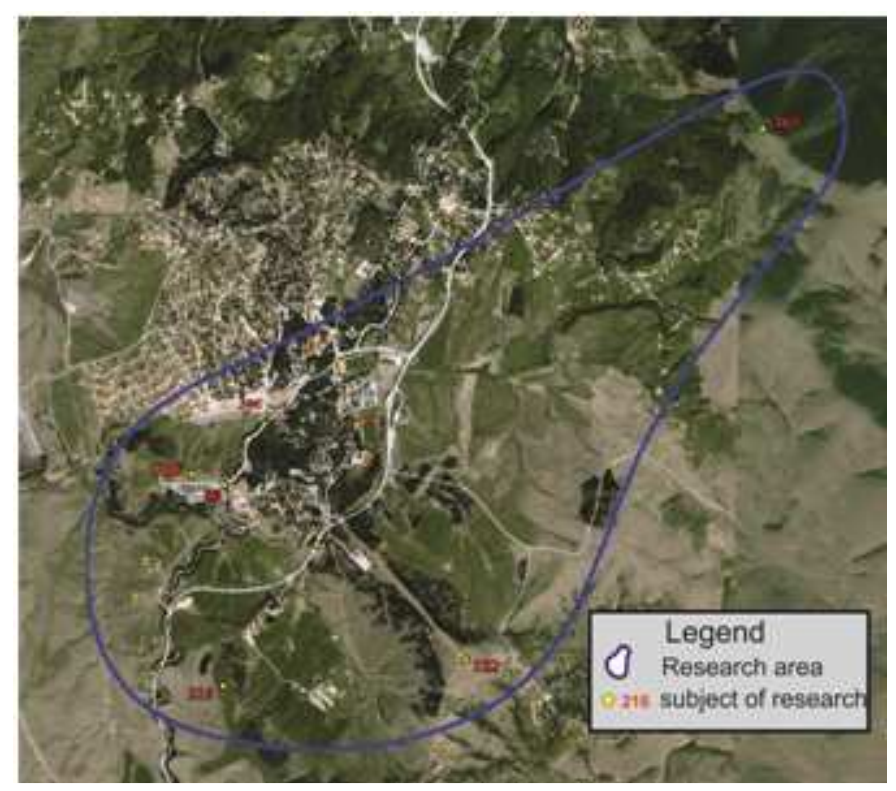

Figure 2. Satellite image of the location "ZLATIBOR"

\section{Research results}

For the purpose of the realization of the research we used a GPS instrument Trimble, model 5700, S/N 0220340219 (Fig. 3). It was a universal double-frequency geodetic GPS receiver with 24 channels. It uses carrier frequencies L1 and L2. The instrument supports only NAVSTAR GPS satellites.

The Trimble 5700 series instrument is constructed following the modular concept, which means that the receiver itself is separated from its antenna. It can be used both in base and rover mode. It owns all necessary characteristics to be used in a CORS network, usually as a rover. The instrument has a declared accuracy of position accuracy of $5 \mathrm{~mm}+0.5 \mathrm{ppm}$ in the static mode, and $10 \mathrm{~mm}+1 \mathrm{ppm}$ in kinematic mode. There is an internal radio inside it that is to be connected to the controller via a cable. It has slots for two batteries and an integrate charger. Its internal memory is 128 MB.
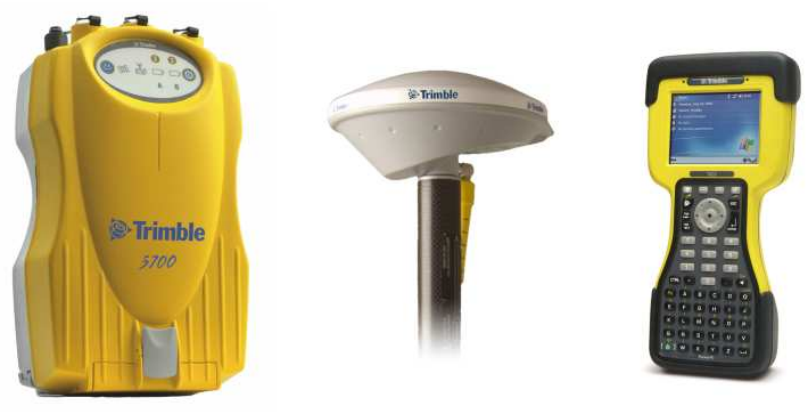

Figure 3. The instrument and the accessories

The antenna used during the experiment realization was Trimble Zephyr, S/N 60133649. Besides the receiver and the antenna, a counterpart of the instrument is a controller Trimble TSC2 (Fig. 3 ), carbon rod with a centric bubble for placing the antenna and spare dipod for mounting the rod under a point to be measured.

In order to establish a geodetic network along the polygon for the students surveying practice, there is a request to perform the works following the methodology for surveying activities and the principles of establishing the geodetic networks using AGROS.

There is a network of fixed points along the polygon used for the students practice. We used that network, so there was no need for the network reconnaissance and stabilization.

We performed the measurements in ten epochs with one day interval between two epochs. The whole campaign lasted from 2013-06-18 to 201306-27.

During the measurements, we were following the directives and the rules prescribed by the professional manual for application of AGROS in basic geodetic works and the survey of real estate [4]. We measured within the period of $30 \mathrm{~s}$ with minimum three repeated measurements at each point in each epoch. Minimal time work is conditioned by the achievement of $2 \mathrm{~cm}$ horizontal and $3 \mathrm{~cm}$ vertical accuracy. We set the maximum PDOP value to 6 . During the observations, we placed the receiver antenna at the top of the rod, with direct centring, while the rod verticality was achieved by the rod's centric bubble.

According the measurement procedure, the field crew was visiting the polygon and performing the measurements at each point. The exception was the first day when, due to technical reasons, it was 
not able to survey all points. That is why we presented only the surveyed points in the results.

We estimated the final coordinates for each measurement epoch separately. We entered the measurement results in the GPS-5 form, where the final coordinates are calculated by means of the arithmetical mean [4].

We controlled the obtained results by comparing the results between ten measurement epochs. After the calculation of the points coordinates, we grouped all obtained results for each point and calculated the intervals of position vectors residuals. The intensity of the position vector residuals (the spatial length residual) was determined in two ways:

1. referred to the zero epoch with coordinates

obtained by static measurements, epoch 2013

(2013-06-19)

2. referred to zero epoch with averaged coordinates from all ten measurement epochs.

In that way we obtained the array of ten spatial length residuals, which we used to draw a conclusion about the average residuals and the intervals of accuracy of obtained results from all ten epochs. Results and spans are given in Tab. 1 and Tab. 2.

Table 1: Parameters of quality control for the first case

\begin{tabular}{llrccc}
\hline \multicolumn{1}{c}{$\mathbf{P t} \#$} & $\mathbf{n}$ & $\begin{array}{r}\boldsymbol{d}_{\boldsymbol{i}} \\
{[\mathbf{m}]}\end{array}$ & $\begin{array}{c}\boldsymbol{\sigma}_{\text {di }} \\
{[\mathbf{m}]}\end{array}$ & $\begin{array}{c}\Delta \mathbf{d}_{\min } \\
{[\mathbf{m}]}\end{array}$ & $\begin{array}{c}\Delta \mathbf{d}_{\max } \\
{[\mathbf{m}]}\end{array}$ \\
\hline 1 & 10 & 0.038 & 0.020 & 0.001 & 0.046 \\
2 & 10 & 0.084 & 0.040 & 0.006 & 0.065 \\
80 & 10 & 0.171 & 0.329 & 0.054 & 0.934 \\
182 & 9 & 0.046 & 0.017 & 0.001 & 0.030 \\
216 & 9 & 0.069 & 0.050 & 0.008 & 0.125 \\
303 & 9 & 0.073 & 0.048 & 0.010 & 0.095 \\
$3 \mathrm{ec}$ & 10 & 0.054 & 0.020 & 0.002 & 0.035 \\
$\mathrm{GRF}$ & 10 & 0.067 & 0.034 & 0.002 & 0.083 \\
\hline
\end{tabular}

Table 2: Parameters of quality control for the second case

\begin{tabular}{cccccc}
\hline $\mathbf{P t} \#$ & $\mathbf{n}$ & $\begin{array}{c}\boldsymbol{d}_{\boldsymbol{i}} \\
{[\mathbf{m}]}\end{array}$ & $\begin{array}{c}\boldsymbol{\sigma}_{d i} \\
{[\mathbf{m}]}\end{array}$ & $\begin{array}{c}\Delta \mathbf{d}_{\min } \\
{[\mathbf{m}]}\end{array}$ & $\begin{array}{c}\Delta \mathbf{d}_{\max } \\
{[\mathbf{m}]}\end{array}$ \\
\hline 1 & 10 & 0.035 & 0.019 & 0.002 & 0.038 \\
2 & 10 & 0.075 & 0.033 & 0.003 & 0.062 \\
80 & 10 & 0.212 & 0.276 & 0.055 & 0.783 \\
182 & 9 & 0.037 & 0.015 & 0.002 & 0.023 \\
216 & 9 & 0.061 & 0.046 & 0.002 & 0.111 \\
303 & 9 & 0.054 & 0.032 & 0.001 & 0.056 \\
$3 \mathrm{ec}$ & 10 & 0.043 & 0.024 & 0.003 & 0.034 \\
$\mathrm{GRF}$ & 10 & 0.043 & 0.033 & 0.000 & 0.085 \\
\hline
\end{tabular}

\section{Discussion and conclusions}

The measurements for the purpose of this research are performed in ten epochs (days), which gives us the opportunity to conclude in what way and how much the measurements differ from each other. If we follow the claims and assumptions that AGROS and its RTK service always provides the 2$3 \mathrm{~cm}$ accuracy, it can be concluded that the differences in the coordinates obtained in each epoch cannot differ more than that. We entered the parameters for the monitoring and control of the measurements into the controller before the realization of the works $\left(\sigma_{\mathrm{p}}<2 \mathrm{~cm}, \sigma_{\mathrm{h}}<3 \mathrm{~cm}\right.$, $\mathrm{PDOP}<6$ ), assuring the registration only those measurements that suffice those criteria.

Experimentally we concluded that the residuals of the coordinates between the certain points epochs differ more than allowed, Tab. $3(2 \mathrm{~cm}$ horizontally and $3 \mathrm{~cm}$ vertically).

Table 3: Spans of the coordinate values by the axis's (without rejecting)

\begin{tabular}{cccc}
\hline $\mathbf{P t} \#$ & $\begin{array}{c}\mathbf{X}_{\mathbf{m a x}}-\mathbf{X}_{\mathbf{m i n}} \\
{[\mathbf{c m}]}\end{array}$ & $\begin{array}{c}\mathbf{Y}_{\mathbf{m a x}}-\mathbf{Y}_{\mathbf{m i n}} \\
{[\mathbf{c m}]}\end{array}$ & $\begin{array}{c}\mathbf{Z}_{\mathbf{m a x}}-\mathbf{Z}_{\mathbf{m i n}} \\
{[\mathbf{c m}]}\end{array}$ \\
\hline 1 & 12.20 & 5.30 & 5.77 \\
2 & 22.47 & 14.07 & 10.17 \\
80 & 18.83 & 71.53 & 91.23 \\
182 & 7.90 & 5.13 & 6.17 \\
216 & 24.10 & 8.00 & 9.23 \\
303 & 13.80 & 8.30 & 12.17 \\
$3 \mathrm{ec}$ & 11.27 & 5.77 & 10.13 \\
GRF & 7.03 & 5.63 & 16.80 \\
\hline
\end{tabular}

After rejecting the values (epochs) that are recognized by testing significantly differ from their mean values, we narrowed the spans, but still there were significant differences overcoming the accuracy prescribed by AGROS-RTK. The spans are given in Tab. 4.

Table 4: The spans of the coordinate values by axis's (with rejecting)

\begin{tabular}{cccc}
\hline $\mathbf{P t} \#$ & $\begin{array}{c}\mathbf{X}_{\mathbf{m a x}}-\mathbf{X}_{\mathbf{m i n}} \\
{[\mathbf{c m}]}\end{array}$ & $\begin{array}{c}\mathbf{Y}_{\mathbf{m a x}}-\mathbf{Y}_{\mathbf{m i n}} \\
{[\mathbf{c m}]}\end{array}$ & $\begin{array}{c}\mathbf{Z}_{\mathbf{m a x}}-\mathbf{Z}_{\mathbf{m i n}} \\
{[\mathbf{c m}]}\end{array}$ \\
\hline 1 & 7.33 & 5.03 & 5.77 \\
2 & 22.47 & 14.07 & 10.17 \\
80 & 7.93 & 3.70 & 8.27 \\
182 & 6.27 & 5.13 & 6.17 \\
216 & 10.00 & 5.03 & 9.23 \\
303 & 8.20 & 8.30 & 12.17 \\
$3 \mathrm{ec}$ & 11.27 & 5.77 & 10.13 \\
GRF & 6.40 & 5.63 & 5.53 \\
\hline
\end{tabular}


From the presented results, one can conclude that, after rejecting the values (epochs) with significant influence on the measurements, the span intervals are narrowed, by not enough to conclude that the differences of the coordinates are insignificant regarding the prescribed accuracy could be obtained by this surveying method.

There were many possible reasons of the differences, and they should be investigated for the whole territory of the Republic of Serbia, which will make the users relaxes from the doubts in the quality of the obtained coordinates. Especially, the errors in receiving satellite signals should be analyzed, together with the errors of registering the huge number of reflexed signals, as well as, the errors in atmosphere parameters, and other corrections received from the permanent stations.

\section{Acknowledgement}

This paper was realized as a part of the project "Studying climate change and its influence on the environment: impacts, adaptation and mitigation" (43007) financed by the Ministry of Education and Science of the Republic of Serbia within the framework of integrated and interdisciplinary research for the period 2011-2014.

\section{References}

[1] K. Vračarić, I. Aleksić i J. Gučević, Geodetski premer, Republički geodetski zavod, 2011, ISBN 978-86-459-0386-3, str. 610.

[2] O. Vasović, J. Gučević, Praktična geodezija 1, Visoka građevinsko-geodetska škola, 2010, ISBN 978-86-7488-120-0, str.324.

[3] K. Vračarić, I. Aleksić, Praktična Geodezija, Geokarta, 2007, ISBN 978-86-459-0311-5, str. 746,

[4] Stručno uputstvo o primeni aktivne geodetske referentne osnove Republike Srbije u osnovnim geodetskim radovima i premeru nepokretnosti, Republički geodetski zavod, br. 95-83/05 od 30.12.2005. godine

[5] Zakon o državnom premeru i katastru. ("Službeni glasnik Republike Srbije",br. 83/92, 53/93, 67/93, 48/94, 12/96,15/96, 34/2001, 25/2002, 2009/2010, $72 / 09$ i $18 / 10$ ),

[6] Volker Schwieger, Mikael Lilje, Rob Sarib, GNSS CORS - Reference Frames and Services, 2009.

[7] www.wikimapia.org 